Е. Ц. Чимитдоржиева, А. А. Жамсаранов. Исследование миграционных процессов в регионе с использованием индекса Морана

УДК 332.1

DOI 10.18101/2304-4446-2020-3-67-74

\title{
ИССЛЕДОВАНИЕ МИГРАЦИОННЫХ ПРОЦЕССОВ В РЕГИОНЕ С ИСПОЛЬЗОВАНИЕМ ИНДЕКСА МОРАНА
}

\author{
(c) Чимитдоржиева Екатерина Цыренжабовна \\ кандидат экономических наук, доцент \\ E-mail: katrin_c@mail.ru \\ (C) Жамсаранов Аюр Арсаланович \\ обучающийся \\ E-mail: zhamaur@gmail.com \\ Бурятский государственный университет имени Доржи Банзарова \\ Россия, 670000, г. Улан-Удэ, ул. Смолина, 24а
}

В статье для анализа миграционных процессов внутри Республики Бурятия использовался пространственный статистический анализ. В настоящее время наблюдается структурирование экономического пространства региона, позволяющее выделить центр, полупериферию и периферию. Это связано с неравномерным распределением факторов производства и результатов экономической деятельности по территории региона, что способствует развитию миграционных процессов. Основным инструментом анализа в работе является коэффициент пространственной автокорреляции, отражающий степень взаимовлияния объектов друг на друга. В результате проведенного исследования были сделаны выводы о наличии пространственного взаимодействия между муниципальными образованиями региона по показателям «численность населения» и «относительный миграционный прирост». Динамика индекса Морана с 2012 по 2019 г. показала усиление кластеризации муниципальных районов по показателю «численность населения».

Ключевые слова: миграция населения; муниципальные образования; индекс Морана; эконометрическое моделирование.

\section{Для цитирования}

Чимитдоржиева Е. Ц., Жамсаранов А. А. Исследование миграционных процессов в регионе с использованием индекса Морана // Вестник Бурятского государственного университета. Экономика и менеджмент. 2020. № 3. С. 67-74.

\section{Введение}

Миграция населения - это явление, характерное для современного общества, как правило, вызванное экономическими, социальными, психологическими причинами. Актуальность исследования обусловлена тем, что растущая «подвижность» населения способна создавать как положительные, так и отрицательные эффекты в экономических системах государств и регионов, а также существенно влиять на демографическую ситуацию в местах исхода и приема мигрантов.

В настоящее время в научной литературе выделяют несколько теорий, объясняющих существование миграционных процессов. Наиболее часто для объяснения миграции как экономического явления упоминается неоклассическая теория 
(М. Фридман, П. Самуэльсон, М.Тодаро, Л. Маружко), теория двойного рынка труда (М. Пиоре) и теория мир-системы (И. Валлерстайн).

Согласно теории И. Валлерстайна, весь мир можно структурировать на центр, полупериферию и периферию [3]. Центр (ядро) включает наиболее развитые страны, обладающие политическим весом. Здесь концентрируется капитал, создаются новые технологии и сложные производства, что обеспечивает достаточно высокий уровень дохода населения [4]. Другими словами, фактор географического положения является существенным при анализе экономических и социальных различий территорий, что в конечном итоге и порождает миграцию населения. Применяя данную теорию, можно предположить, что миграционный поток будет направлен из периферии в полупериферию и центр. Экономические теории, применяемые для описания международной миграции, могут использоваться для анализа миграционных процессов внутри конкретной страны.

Основным инструментом анализа миграционного потока в данной работе выступает индекс Морана. Данный показатель отражает степень пространственной зависимости между значениями одной и той же переменной в разных местах пространства [10].

Таким образом, использование инструментов пространственной эконометрики при изучении проблем миграции способно учесть фактор географического положения и дать более точные статистические оценки.

Целью работы является исследование внутрирегиональных миграционных процессов с использованием индекса Морана.

\section{Методы исследования}

Пространственный статистический анализ предполагает наличие определенного взаимодействия между объектами исследования. Так, на величину миграционного потока в муниципальном районе может влиять величина миграционного потока в соседних районах. Сила и направление такого взаимодействия могут быть определены с помощью пространственных коэффициентов автокорреляции, которые, в свою очередь, рассчитываются с применением матриц пространственных весов [9].

В настоящей работе для формализации взаимодействия между районами Республики Бурятия использовались две матрицы - матрица граничных соседей $W$ и матрица ближайших соседей $\widetilde{W}$. Элементы первой матрицы задаются по формуле $[5$, с. 20]

$$
w_{i j}=\left\{\begin{array}{l}
1, \text { если } i \text { граничит с } j, \\
0, \text { в других случаях. }
\end{array}\right.
$$

Матрица граничных соседей является самым простым способом учета пространственного фактора. Здесь учитываются все соседи, которые непосредственно граничат с объектом [1].

Элементы второй также принимают два значения

$$
\widetilde{w}_{i j}(k)=\left\{\begin{array}{c}
0, \text { если } i=j \\
1, \text { если } d_{i j} \leq d_{i}(k) \\
0, \text { если } d_{i j}>d_{i}(k)
\end{array} .\right.
$$


Е. Ц. Чимитдоржиева, А. А. Жамсаранов. Исследование миграционных процессов в регионе с использованием индекса Морана

Согласно формуле (2) для каждого района должно быть учтено $k$ ближайших соседей. Для рассматриваемого объекта расстояние до $i$-го соседа считается той границей, за которой взаимодействия не учитываются [5, с. 21].

Количественной характеристикой пространственного взаимодействия является коэффициент пространственной автокорреляции, а именно индекс Морана (I), который определяется по формуле:

$I=\frac{n}{S_{0}} \frac{\sum_{i}^{n} \sum_{j}^{n} w_{i j}\left(Y_{i}-\bar{Y}\right)\left(Y_{j}-\bar{Y}\right)}{\sum_{i}^{n}\left(Y_{i}-\bar{Y}\right)^{2}}$,

где $N$ - число муниципальных районов; $W_{i j}$ - элемент матрицы пространственных весов для районов $i$ и $j ; \bar{Y}-$ среднее значение показателя; $Y$ - анализируемый показатель.

Результаты исследования

Среднегодовая численность постоянного населения в 2019 г. в Республике Бурятия составляла 984,6 тыс. чел. Население по территории региона распределено неравномерно. Большая часть населения проживает в г. Улан-Удэ и в прилежащих к нему районах: Иволгинском, Заиграевском, Тарбагатайском. Удельный вес населения, проживающего на этой территории, составляет $57,7 \%$ общей численности населения республики. Основной результат экономической деятельности — валовой региональный продукт (ВРП) в 2016 г. составил 199 225,5 млн руб. Распределение ВРП также неравномерно по территории региона. Одна из причин кроется в неоднородности распределения факторов производства. Так, в республике наблюдается неравномерное распределение численности занятых в экономики вследствие неравномерного распределения населения, неоднородного распределения основных фондов и инвестиций в основной капитал [6].

Таким образом, республику можно поделить на три зоны: центр, полупериферия, периферия. Центром региона является г. Улан-Удэ и прилежащие в нему районы, полуперифиерия включает районы центральной и южной части региона, не вошедшие в зону «центр», к периферии можно отнести северные районы, а также Окинский район.

В настоящей работе использованы два вида данных: численность постоянного населения в муниципальных районах с 2012 по 2019 г. и относительный миграционный прирост населения в муниципальных образованиях с 2012 по 2018 г.

Для данных первого типа была использована матрица граничных соседей. Применение этого инструмента имеет свои ограничения, входящие в анализ объекты должны быть примерно одинаковой площади и иметь сопоставимые показатели по численности населения, чего нельзя сказать о муниципальных образованиях республики. Город Улан-Удэ имеет малую площадь и высокую плотность населения по сравнению с другими муниципальными образованиями. По этой причине в исследовании с применением матрицы граничных соседей участвовали только муниципальные районы республики.

Значения коэффициента пространственной автокорреляции за 2012-2019 гг., рассчитанного по матрице граничных соседей за 2012-2019 гг., представлены в табл. 1: 
Таблица 1

\begin{tabular}{|l|c|c|c|c|c|c|c|c|}
\hline \multicolumn{1}{|c|}{ Год } & $\mathbf{2 0 1 2}$ & $\mathbf{2 0 1 3}$ & $\mathbf{2 0 1 4}$ & $\mathbf{2 0 1 5}$ & $\mathbf{2 0 1 6}$ & $\mathbf{2 0 1 7}$ & $\mathbf{2 0 1 8}$ & $\mathbf{2 0 1 9}$ \\
\hline $\begin{array}{l}\text { Индекс } \\
\text { Морана }\end{array}$ & 0,327 & 0,336 & 0,347 & 0,360 & 0,370 & 0,379 & 0,393 & 0,398 \\
\hline Статистика Z & 2,366 & 2,113 & 2,180 & 2,253 & 2,312 & 2,366 & 2,432 & 2,464 \\
\hline
\end{tabular}

Расчеты показали, что в регионе отмечается положительная пространственная автокорреляция, причем наблюдается усиление пространственного взаимодействия между муниципальными районами.

Диаграмма Морана, построенная для данных 2019 г., представлена на рис. 1.

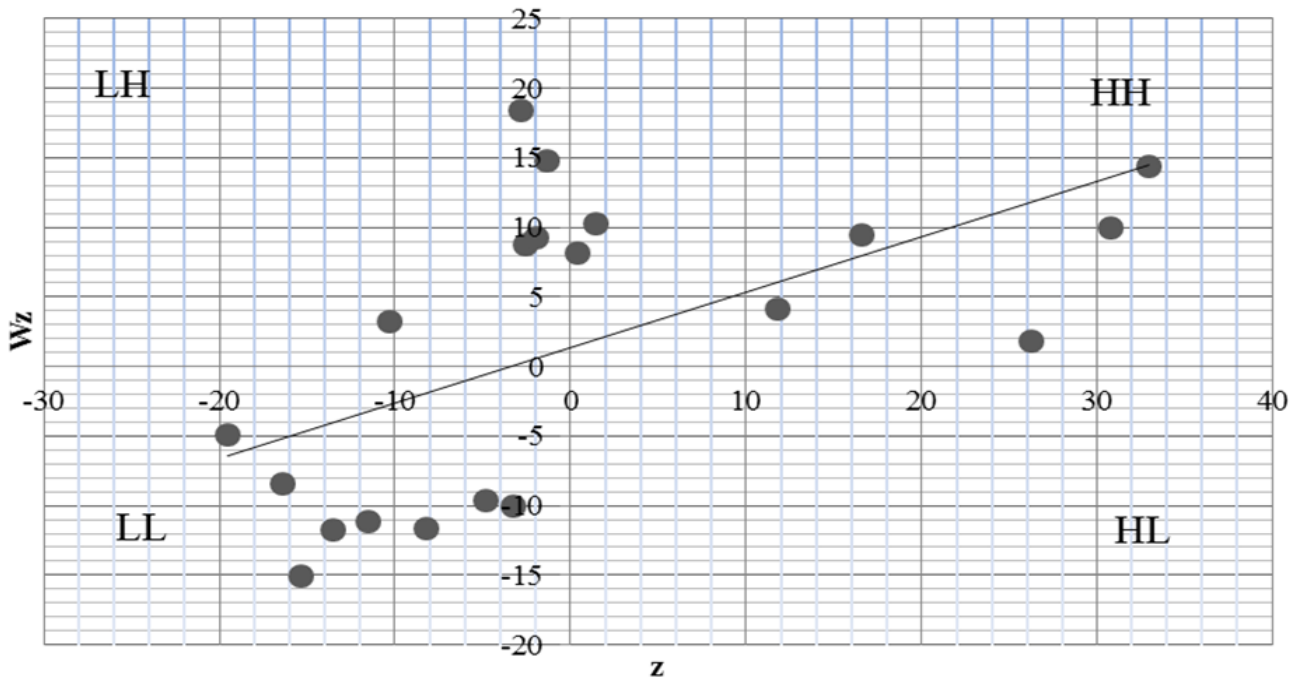

Рис. 1. Диаграмма Морана (матрица граничных соседей) 2019 г.

Согласно данным проведенного исследования, существенных изменений в распределении районов по сравнению с 2017 г. не выявлено [7]. Наличие положительной пространственной автокорреляции позволяет кластеризовать районы республики по показателю «численность населения». В квадрант НН попали районы, принадлежащие ядру и полупериферии региона, районы квадранта LH принадлежат полупериферии. B квадрант LL вошли муниципальные образования периферии.

Таким образом, можно предположить, что районы, входящие в квадрант НН, будут иметь, как правило, положительный миграционный прирост в отличие от районов, попавших в квадрант LL.

Анализ миграционного прироста с 2000 по 2018 г. показал преобладание оттока населения из республики (рис. 2). 
Е. Ц. Чимитдоржиева, А. А. Жамсаранов. Исследование миграционных процессов в регионе с использованием индекса Морана

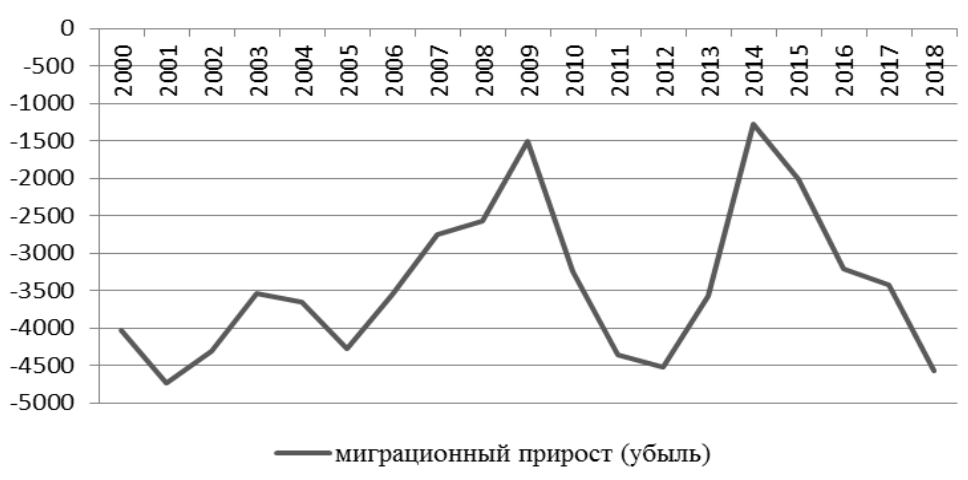

Рис. 2. Миграционный прирост (убыль) населения с 2000 по 2018 г., чел.

Наименьшие значения убыли населения наблюдаются в 2009 г. и в 2014 г., что связано в первую очередь со снижением темпов выбытия населения из региона. Говорить о случайности или закономерности этого явления достаточно сложно (рис. 3).

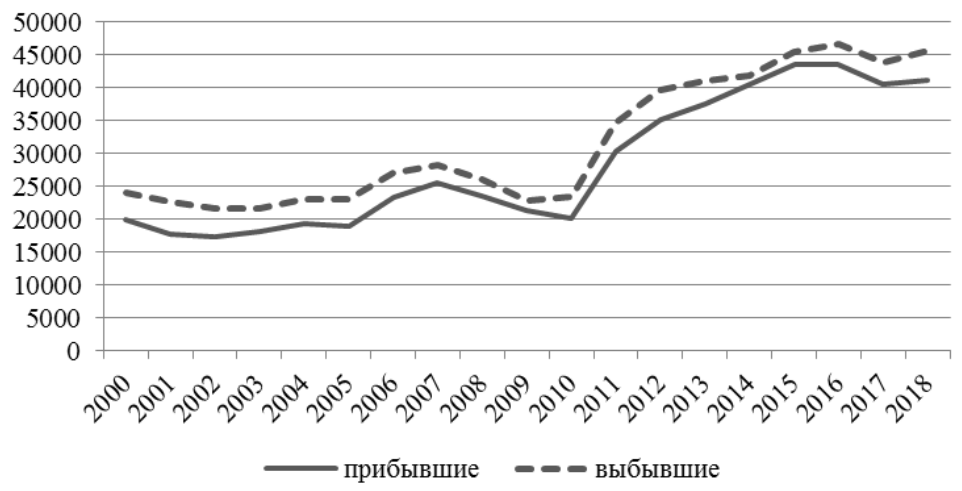

Рис. 3. Численность прибывших и выбывших с 2000 по 2018 г., чел.

С 2008 по 2017 г. удельный вес перемещений в границах республики колебался от 57,9 до 64,5\%. С января по март 2020 г. удельный вес составил 67,6\% общего количества перемещений. Наиболее интенсивный приток мигрантов наблюдается в центральных районах: Тарбагатайском, где миграционный прирост составил 30,3 промилле, Иволгинском районе - 28,5 промилле, а также Заиграевском - 1,2 промилле. В г. Улан-Удэ интенсивность миграционного потока составила 4,3 промилле. Наибольшая интенсивность оттока отмечена в северных районах. Так, в 2017 г. отток на 1000 населения составил в Муйском районе 37,28 промилле, Северо-Байкальском районе - 28,61, Курумканском - 22,95, Баунтовской - 15,86. Следует отметить, что существенных изменений в миграционном движении населения внутри республики не произошло [8].

Таким образом, районы, входящие в квадрант НН, как правило, имеют положительный миграционный прирост или незначительный миграционный отток. В квадранте LL находятся муниципальные образования, в которых наблюдаются самые высокие показатели по миграционному оттоку населения. Следовательно, 
основной внутрирегиональный поток мигрантов направлен из периферии и полупериферии в центр региона.

Для более точной оценки пространственного взаимодействия между муниципальными образованиями был использован показатель «относительный миграционный прирост», в исследование были включены г. Улан-Удэ и Северобайкальск. Построена матрица ближайших соседей, рассчитаны расстояния между муниципальными образованиями республики, причем расчет расстояний производился с помощью программного обеспечения GoogleКарты, за расстояния взяты дистанции между административными центрами районов. В таблице 2 представлены результаты расчета индекса Морана по показателю «относительный миграционный прирост».

Таблица 2

Значения коэффициента пространственной автокорреляции, рассчитанного по матрице ближайших соседей за 2011-2018 гг.

\begin{tabular}{|l|c|c|c|c|c|c|c|c|}
\hline \multicolumn{1}{|c|}{ Год } & 2011 & 2012 & 2013 & 2014 & 2015 & 2016 & 2017 & 2018 \\
\hline $\begin{array}{l}\text { Индекс } \\
\text { Морана / }\end{array}$ & 0,318 & 0,271 & 0,376 & 0,349 & 0,312 & 0,343 & 0,428 & 0,313 \\
\hline Статистика Z & 2,187 & 1,963 & 2,126 & 2,627 & 1,987 & 2,334 & 1,963 & 2,263 \\
\hline
\end{tabular}

В регионе наблюдается умеренная положительная пространственная автокорреляция по показателю «относительный миграционный прирост». Индекс Морана, рассчитанный по индикатору «относительный миграционный прирост», в отличие от аналогичного, рассчитанного по показателю «численность населения», не имеет явно выраженной тенденции, однако с 2012 по 2017 г. наблюдалось усиление пространственных эффектов. На рис. 4 представлена диаграмма Морана.

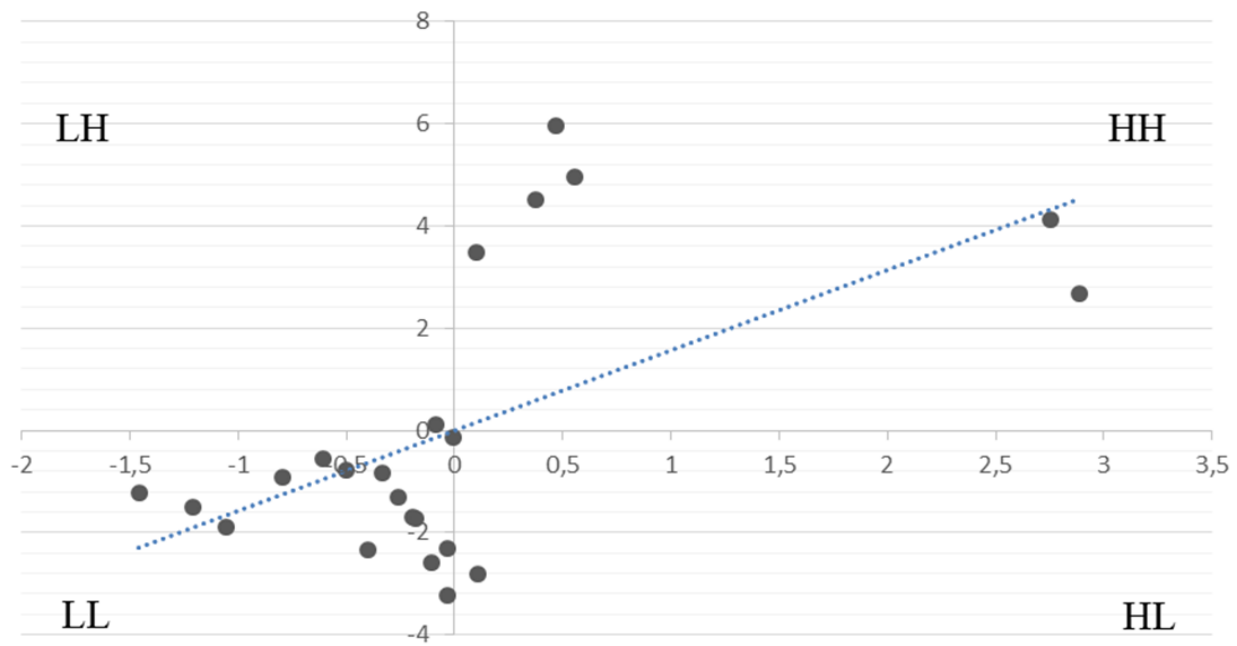

Рис. 4. Диаграмма Морана (матрица ближайших соседей) 2018 г. 
Квадрант LH содержит только Мухоршибирский район. Квадрант HL также содержит один район - Баунтовский. Необходимо отметить, что в 2018 г. миграционный отток населения из этого муниципального района сократился в 2 раза, что стало причиной «перехода» из квадранта LL в квадрант HL. В квадрант НН попали г. Улан-Удэ, Заиграевский, Иволгинский, Кабанский, Прибайкальский, Тарбагатайский районы. Соседи, определяемые с помощью соответствующей матрицы, также имеют высокие значения относительного миграционного прироста. В левом нижнем квадранте LL показаны районы с низким относительным миграционным приростом.

Таким образом, движение населения внутри региона направлено из периферии и полупериферии в центр, наблюдается кластеризация муниципальных образований по численности населения и характеру миграционного потока, причем в первом случае отмечается тенденция к усилению кластеризации, то есть к увеличению разрыва между лидерами и отстающими.

\section{Литература}

1. Балаш В. А., Файзлиев А. Р. Пространственная корреляция в статистических исследованиях // Вестник Саратовского государственного социально-экономического университета. 2008. № 4(23). С. 122-125.

2. Вакуленко Е. С. Введение в пространственную эконометрику / М.: НИУ ВШЭ, 2013. [Электронный pecypc]. URL: http://pokrovka11.files.wordpress.com/ 2013/01/spatial_econometrics.pdf (дата обращения: 13.07.2019).

3. Валлерстайн И. Анализ мировых систем и ситуация в современном мире / пер. англ. П. М. Кудюкина; под общ. ред. Б. Ю. Кагарлицкого. СПб.: Университетская книга, $2001.416 \mathrm{c}$.

4. Новиков К. Е. Мир-системная теория И. Валлерстайна: анализ идейных истоков спорных суждений о российской истории // Социологический журнал. История социологии. 2015. Т. 21, № 2. С. 130-149.

5. Файзлиев А. Р. Математические методы и модели анализа пространственной структуры системы городской торговли: дис. ... канд. экон. наук. Волгоград, 2014. 178 с.

6. Чимитдоржиева Е. Ц. Статистический анализ неравномерности экономического развития муниципальных образований Республики Бурятия // Вестник Бурятского государственного университета. Экономика и менеджмент. 2017. Вып. 3. С. 17-25.

7. Чимитдоржиева Е. Ц., Санковец А. А. Оценка пространственного межмуниципального взаимодействия на основе индекса Морана // Инновационные научные исследования: теория, методология, практика: сборник XVIII Междунар. науч.-практ. конф. Пенза: Наука и просвещение, 2019. С. 127-130.

8. Шевцова Е. В., Дмитриева А. К. Миграционная политика Республики Бурятия: сценарные подходы // Вестник Тюменского государственного университета. Социальноэкономические и правовые исследования. 2016. Т. 2, № 2. С. 59-71.

9. Fingleton B. Regional economic growth and convergence: insights from a spatial econometric, in Anselin L., Florax R. and Rey S. (Ed.) Advances in Spatial Econometrics. Berlin: Springer, 2016. $158 \mathrm{p}$.

10. Getis A., Mur J., Zoller H. (ed.) Spatial Econometrics and Spatial Statistics. London: Palgrave, 2014. $316 \mathrm{p}$. 


\section{STUDY OF MIGRATION PROCESSES IN THE REGION}

\section{USING MORAN'S INDEX}

Ekaterina Ts. Chimitdorzhieva

Cand. Sci. (Econ.), A/Prof.

E-mail: katrin_c@mail.ru

Ayur A. Zhamsaranov

Student

E-mail: zhamaur@gmail.com

Dorzhi Banzarov Buryat State University

24a Smolina St., Ulan-Ude 670000, Russia

To analyze migration processes in the Republic of Buryatia we have used spatial statistical analysis. There has been observed the structuring of economic space in the Republic of Buryatia, and this makes it possible to separate the center, semi-periphery and periphery. This is due to the uneven distribution of the production factors and the results of economic activity throughout the region, which contributes to the development of migration processes. The coefficient of spatial autocorrelation is the main tool for analysis, it reflects the degree of mutual influence of objects on each other. As a result of the study, we have concluded that there is spatial interaction between the municipalities of the region in terms of "population size" and "relative migration balance". The dynamics of the Moran's index from 2012 to 2019 showed an increase in the clustering of municipal districts in terms of "population size".

Keywords: population migration; municipalities; Moran's index. 